\title{
PERSPECTIVES OF BUSINESS IN TECHNOLOGICAL, HUMAN RESOURCE, MARKETING AND SOCIAL PROGRESSES
}

\author{
Prof. Peihua Fu ${ }^{1}$, Tchamy Jonathan ${ }^{2 *}$, Najma Bano ${ }^{3}$ \\ ${ }^{1.2}$ School of Management and E-_Business, Zhejiang Gongshang University, Hangzhou, China. \\ ${ }^{3}$ New Cambridge Academy, Multan, Pakistan.
}

johancamron@outlook.com

Keywords: social responsibility; business;management;

globalization

\begin{abstract}
A B S T R A C T
Globalization is shaping the economic and business actions. A lot of barometer models are created to understand these actions and issues. One of the models is ability-motivation-opportunity (AMO. Definitions of these actions vary, but all of them have the same idea about this topic. After a review of relevant literature this article finds that Globalization transforms the world into a single global market of goods and services and erases all possible boundaries between customers and manufacturers. All existing companies compete in the international market a priority; in this regard it is necessary to employ a qualitative new approach to the development of a competitive international company strategy under conditions of current economic realities.
\end{abstract}

Citation: Prof. Peihua Fu, Tchamy Jonathan, Najma Bano (2018). Perspectives Of Business In Technological, Human Resource And Marketing And Social Progresses. International Journal of Advanced Multidisciplinary Scientific Research (IJAMSR) ISSN:2581-4281 Vol 1, Issue 9, November, 2018, \#Art.920, pp 71-75 
Introduction:

Good leadership means a lot in today's globalization challenges. Leadership today is viewed in dual perspective in a diagonal way. First, as a special case of interpersonal influence through which a person or group of people does what a leader wants them to do, in other words, leadership is a process of predominantly non forceful influence in the direction of achieving a group or organization's goals. Second, leadership can be perceived as a certain set of qualities attributed to those who successfully influence or affect others (Schermerhorn George., Hunt J., Osborne R., 2004). On the other hand, IT implementation within companies brings about another advantage when it comes to the number of employees in the organization. IT will reduced by the fact that technology has taken over. It also increases the amount of crime rate in a country as many people are not employed affecting the economy as whole (Eija, 2011). This paper is aimed to highlight the main points of relevant literature to assess how important technology and management are for success of enterprises.

\section{Literature Review}

IT systems are more reliable when it comes to backing up information as it stores every piece of information that it has been used for. In other words machines do not forget easily as humans do. IT systems are more secure as compared to humans and with the organizations sensitive information, as employees may get fired or share this information with other competitive companies giving the organization a great disadvantage. They are also more convenient as they can process information in multiple ways as humans use as certain manner that they have been taught or are more comfortable using (Taiwo,
J.N).

In today's society consumer culture is everywhere and we could probably not be able to survive without it. It turned into such an important part of our lives that some people still develop their career in it (Arnold \& Thompson, 2005). So in order to envy and emulate the people of high social status, people with a low social statues use their consumption, trying to imitate (Philips, 2003). Recognition of community wants is one of the social responsibilities of companies to pay attention towards emerging needs (Hao, Farooq, \& Zhang, 2018).

For other type of the use of consumption of identity building is becoming distinguished in the society and the majority of these consumers are wealthy people with a high social status.

So the choice of a product is a way of expressing ourselves, either our real personality or what we want the society to think of us, if you purchase a kitchen and you choose its different color that is because it fits with your warm personality, but if you purchase a watch and you choose it a Rolex then you want to highlight your high social status or remain distinguished (Philips, 2003).

A leader is obliged to take into account the interests of adherents of various cultures as much as possible. A favorite of international importance is obliged to motivate employees to achieve results by increasing their consciousness in the perception of the significance of the designated goal, giving them the opportunity to combine their own personal interests with a joint goal, forming an atmosphere of trust and mutual respect, promoting their self-development and taking into account their cultural characteristics. 


\section{International Journal of Advanced Multidisciplinary Scientific Research (IJAMSR) ISSN:2581-4281}

With effective communication systems speeds up the processing of information from one person to the next and can be rapidly addressed and solved without any barriers. This will give benefits not only to the company, but also to the economy as an added advantage over many competitive companies in different geographical areas. Information systems improve organizational innovation. Benevolence trust comes from one party's belief regarding a partner's empathy about the relationship. Benevolence trust does not care profit taking and does not have negative insight about their importer (GU et al., 2016). Trusting parties put positive feelings between each other. It talks about good morality and respect between these sides. The customer perceived value of that product due to its appropriate availability tends to enhance that is the ultimate key factor for enhancing customer loyalty and brand image. An effective distribution strategy does not include steps only to make availability of product to existing customers and to satisfy them rather it also involved, such activities that attract new customers through an extensive distribution because the product that is available in the market at the right time and in the right location has more chances to be accepted and purchased by customers. Additionally, the satisfied existing customers due to appropriate availability of product also tend to attract new one thus enhancing the new sources of profit for the company (Vickery, Jayaram, Droge, \& Calantone, 2003). These satisfied existing customers and new customers are ultimate source of revenues for the company and thus for enhancing firm's financial performance and this contribution of effective distribution strategy is not confined to financial performance only, but also nonfinancial performance.
Social practices might be found in the worldwide commercial center for example the type of clothing and taking coffee, yet the hidden qualities that clarify intentions in purchasing these are not worldwide. While in a few societies customers may drink Coca-Cola to extinguish their thirst, in others they may do as such for status reasons. Worldwide advertisers need to realize these distinctions to create powerful worldwide promoting and publicizing efforts (Mooji, 2015). International marketers should have a broader knowledge of the delicate to social differences amongst various cultures. To regard the privilege to culture by the purchasers in different societies and commercial centers, advertisers ought to comprehend that their clients have a privilege to maintain, practice, and identify with their own culture.Hao, Farooq \& Sun (2018) explained culture in two dimensions: Cultural Diversity and cross cultural learning interest. Both are very important for future study.

Few people carryout Innovation Driven Enterprise (IDE) entrepreneurship because of the high cost. The SMEs are mostly family businesses that serve the local market and these are started by most of the entrepreneurs in Africa because they can operate at low cost. These employ many of the people in their localities. Entrepreneurship can create jobs, generate wealth and encourage economic growth.

Environmental sustainability is very important (Hao, Zhang \& Farooq, 2018) for the discussion of globalization. Initially, it is necessary to analyze the situation in the target segment of the international market. To do this, it is necessary to assess the state of the environment of the international market segment, the 


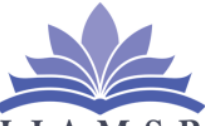

I J A M S R

International Journal of Advanced Multidisciplinary Scientific Research (IJAMSR) ISSN:2581-4281

state of the organization and its competitors, as well as understand the level of requirements for product quality and its value for international clients.

Globalization has brought about, many global players to voice their claim to "a right to culture" in international businesses in line with what was foreseen by Tian (2011) that national culture is a vital aspect in moving economic development, demographic behavior, and general International business policies across the world. As a result, if globalization is inevitable, then crossacculturalization also will be inevitable. While the globalization is now the talk of the day distinctions between national markets are weakening and in some instances disappearing altogether. This clearly shows that International marketing and communication is being widely adopted. The cultural variation among nations, regions, and ethnic groups are getting stronger, which suggests that International marketing and communication managers to have to be educated regarding cultural variations across the divide (Tian, 2011). Communication of people from a similar culture is regarded as troublesome. With this in mind, crosscultural communication of individuals from distinct background and values is without doubt troublesome, with a level of miscommunication being relatively unavoidable.

\section{Discussion and Conclusion:}

We have reviewed the relevant literature about patterns of entrepreneurship, leadership and culture in technological managerial perspective. Entrepreneurs should have various skills such as management skills and sales skills. They should be able to adapt to the new behaviors, entrepreneurship deals with handling new challenge. These skills can be learnt from the various institutions such as universities. Entrepreneurs should be effective communicators. People from different places to communicate differently and use information differently. The education offered is to train the students to become job seekers, but this should be improved and peopled be taught to become job creators. This will encourage entrepreneurship and promote economic growth and development.

IT systems are more reliable when it comes to backing up information as it stores every piece of information that it has been used for. In other words machines do not forget easily as humans do. IT systems are more secure as compared to humans and with the organizations sensitive information, as employees may get fired or share this information with other competitive companies giving the organization a great disadvantage. They are also more convenient as they can process information in multiple ways as humans use as certain manner that they have been taught or are more comfortable using (Taiwo, J.N).

The algorithm for the development of international company strategy, taking into account the specific conditions for the development at the supranational level, is proposed to develop the international company strategy. The globalization trends of our electronic era are turning the world into a "global village". They make everything and everyone available anywhere and anytime. While building a model of leadership in a 


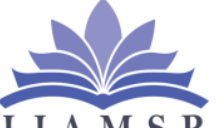

International Journal of Advanced Multidisciplinary Scientific Research (IJAMSR) ISSN:2581-4281

multicultural team from the standpoint of increasing the productivity of cross-cultural interaction, the theoretical basis used the theory of new leadership, which were supplemented by the consideration of new leadership properties and behavior demanded in the global context in which the leader of an international company. This model is the most promising in the context of globalization of the world economy and the expansion of international cooperation. It allows you to find the optimal combination and balance of interests between the leader with certain leadership abilities, followers and the situation in which the leader and members of the collective interact in a global context.

\section{Reference:}

1) Arnold, E., \& Thompson, J. (2005). Consumer culture theory(CCT): Twenty years of research. Journal of Consumer Research,31, 868-882.

2) Gu, F. F., Wang, J. J., \& Wang, D. T., (2016). Industrial Marketing Management. The role of representatives in cross-cultural business to-tobusiness relationships.

3) Hao, Y., Farooq, Q., \& Sun, Y. (2018). Development of a theoretical framework and measures for the role of social media in realizing corporate social responsibility through native and non-native communication modes: Moderating effects of crosscultural management. Corporate Social Responsibility and Environmental Management 25(4), 704-711. https://doi.org/10.1002/csr. 1523

4) Hao, Y., Farooq, Q., \& Zhang, Y. Unattended social wants and corporate social responsibility of leading firms: $R$ elationship of intrinsic motivation of volunteering in proposed welfare programs and employee attributes. Corporate Social Responsibility and Environmental Management. 2018;1-10. https://doi.org/10.1002/csr.1681

5) Hao, Y., Zhang, Y., \& Farooq, Q. (2018). The contribution of leading firms in environmental sustainability: dampening the detrimental effect of political capital ties. International Journal of Environmental Science and Technology, 15(12), 2581-2594. https://doi.org/10.1007/s13762-0182035-x.

6) Mooij, M. D. (2015). Cross-cultural research in international marketing: Clearing up some of the Confusion. International Marketing Review.

7) Philips, C. (2003). how do consumers express their identity through the choice products that They buy? University of bath Journal ,20.

8) Shermerhorn George., Hunt J., \& Osborne R.,(2004). Organizational behavior,Kotter, J. P., (1990). A Force for Change : How Leadership Differs from Management.

9) Taiwo, J.N. Effect of ICT on accounting information system and organizational performance : the application of information and communication technology on accounting information system.

10) Vickery, Shawnee K, Jayaram, Jayanth, Droge, Cornelia, \&Calantone, Roger. (2003). The effects of an integrative supply chain strategy on customer service and financial performance: an analysis of direct versus indirect relationships. Journal of operations management, 21(5), 523-539. 